\title{
Predicting Transpiration Response to Climate Change: Insights on Physiological and Morphological Interactions that Modulate Water Exchange from Leaves to Canopies
}

\author{
William L. Bauerle ${ }^{1}$ and Joseph D. Bowden \\ Department of Horticulture and Landscape Architecture, Colorado State University, 1173 Campus Delivery, \\ Fort Collins, CO 80523-1173
}

Additional index words. Acer rubrum, leaf temperature, leaf width, modeling, water vapor transfer, wind

\begin{abstract}
Leaves are key factors in the global water exchange cycle. As the primary control interface involved in regulating water loss, understanding the relative influence of leaf morphological and physiological transpiration factors is critical to accurate evapotranspiration predictions. We parameterized a three-dimensional array model, MAESTRA, to establish a link from the leaf to canopy scale and attempted to isolate and understand the interplay among variation in morphological and physiological variables affecting transpiration. When physiological differences were accounted for, differences in leaf width $\left(L_{\mathrm{w}}\right)$ among Acer rubrum $\mathrm{L}$. genotypes significantly affected leaf temperature and transpiration under slow to moderate wind velocities. In instances, $L_{\mathrm{w}}$ variation among genotypes resulted in a $25 \%$ difference in transpiration. This study demonstrates how simple morphological traits like $L_{\mathrm{w}}$ can provide useful selection criteria for plant breeders to consider in a changing climate.
\end{abstract}

The boundary layer governs the diffusion of gases between vegetation and the atmosphere at the leaf and whole crown scale. Although Prandtl is credited with the introduction of boundary layer theory in 1904 (Schlichting and Gersten, 2004), the first leaf model incorporating physically based boundary layer concepts was not introduced until 52 years later (Raschke, 1956). Raschke's pioneering work identified the influence of leaf size (e.g., leaf width) on the leaf energy budget through sensible heat and water exchange; however, consideration for boundary layer effects on the diffusion pathway of the leaf waxed and waned thereafter (Schuepp, 1993). Nonetheless, leaf size and within-crown spatial distribution affect the boundary layer conductance of the canopy and are a key element in modulating the soil-plant-atmosphere water transport process at the earth's surface (e.g., Monteith and Unsworth, 2008).

The thickness of the boundary layer interacts with stomatal conductance $\left(g_{\mathrm{s}}\right)$ to control transpiration. At scales larger than the leaf, however, the boundary layer control on transpiration can become more important than genotypespecific stomata expressions. For example, it is commonly accepted that under ventilated conditions at the leaf surface, stomata control transpiration in response to vapor pressure

Received for publication 8 Oct. 2010. Accepted for publication 2 Nov. 2010.

We thank Parsons Nursery for donating the trees for this study and the following funding agencies for partial support of this study: USDA-NIFA, Specialty Crops Research Initiative Grant (Award No. 2009-51181-05768) and USDA-FNRI, Cooperative Agreement (Agreement No. 58-6618-2-0209). This paper was part of the colloquium "Water Management and Plant Performance in a Changing Climate" held 4 Aug. 2010 at the ASHS Conference, Palm Desert, CA, and sponsored by the Water Utilization and Plant Performance in a Changing Climate (WUM) Working Group.

${ }^{1}$ To whom reprint requests should be addressed; e-mail bauerle@colostate.edu. deficit (VPD) (e.g., Bunce, 1985; Katul et al., 2009). In contrast, it is the thickness of the boundary layer that often controls transpiration at the stand scale, a consequence of environment and canopy structure interactions (Hinckley et al., 1994; Jarvis and McNaughton, 1986; Meinzer et al., 1995). Thus, there remains a need to understand the relative interaction between canopy controls over water loss and how leaf morphology and physiology scale up to whole plant and canopy scales (Monteith, 1989).

Our objective was to assess the transpiration response among genotypes of a common horticulture tree crop through investigation of the leaf-to-atmosphere microclimate interactions in a changing climate. We used a three-dimensional spatially explicit individual plant process model, MAESTRA (MultiArray Evaporation Stand Tree Radiation A) (Wang and Jarvis, 1990) to investigate and separate the contributions of morphological and physiological transpiration parameters in leaf and canopy scale transpiration predictions. We parameterized the model on a genotypespecific basis from measurements on commercially available Acer rubrum L. (red maple) cultivars. We tested the hypothesis that variation in $L_{\mathrm{w}}$ within red maple considerably modified boundary layer conductance, leaf temperature, and transpiration aside from physiological differences.

\section{MATERIALS AND METHODS}

Site and plant material. Measurements were taken on South Carolina grown red maple cultivars ['Summer Red' (SR), 'October Glory' (October Glory®) (OG), 'Autumn Flame' (AF), and 'Franksred' (Red Sunset $\left.{ }^{\circledR}\right)$ (RS) and one Freeman maple cultivar, Jeffersred (Autumn Blaze ${ }^{\circledR}$ ) (AB) and used to parameterize MAESTRA. Plants were grown in 114-L Spin Out-treated plastic pots containing a mixture of 20:1 pine bark to sand (by volume) fertilized with $8.3 \mathrm{~kg} \cdot \mathrm{m}^{-3}$ of Nutricote ${ }^{T M}$ 20N-3.0P-8.3K Type 360 (Chisso-Asahi Inc.,
Tokyo, Japan) on an outdoor gravel pad. Trees were placed in a completely randomized design and spaced $1.5 \mathrm{~m}$ center to center in rows $1.5 \mathrm{~m}$ apart. The continuous stand consisted of $\approx 3 \mathrm{~m}$ tall equal age saplings of five genotypes ( $\mathrm{n}=20$ trees per genotype). Each tree was watered three times daily to near container capacity with $360^{\circ}$ pressure compensating microemitters (ML Irrigation Inc., Laurens, SC). Substrate volumetric water content was monitored daily in each container at $10 \mathrm{~cm}$ and $20 \mathrm{~cm}$ below the substrate surface in four pre-drilled locations on opposite sides of the container (Theta Probe Type ML2; Delta- T Devices, Cambridge, UK) to verify that root zone volumetric water content was maintained within a previously determined well-watered range ( 0.4 to $0.5 \mathrm{~m}^{3} \cdot \mathrm{m}^{-3}$ )

Measurements of leaf-level and whole tree morphology and physiology. Leaf physiology was quantified using a portable steady-state gas exchange system (CIRAS-I; PP Systems Inc., Amesbury, MA); cuvette conditions were controlled at $25^{\circ} \mathrm{C}$ air temperature, $1.3 \mathrm{kPa}$ VPD, saturating photosynthetic photon flux (1000 $\mu \mathrm{mol} \cdot \mathrm{m}^{-2} \cdot \mathrm{s}^{-1}$ or greater), and varied carbon dioxide $\left(\mathrm{CO}_{2}\right)$ levels. Photosynthetic activity was assessed by constructing net photosynthesis versus intercellular $\mathrm{CO}_{2}$ concentration curves from which maximum carboxylation rates $(\mu \mathrm{mol}$. $\mathrm{m}^{-2} \cdot \mathrm{s}^{-1}$ ) and maximum electron-transport rates $\left(\mu \mathrm{mol} \cdot \mathrm{m}^{-2} \cdot \mathrm{s}^{-1}\right)$ were estimated. Leaf reflectance and transmittance were estimated with a SPAD meter for quantum yield calculations (Model 502 Minolta Camera Inc., Ramsey, NJ). Detailed descriptions of leaf-level morphology and physiology have been described in Bauerle et al. (2003, 2007). Whole-tree morphology and physiology are as described in Bauerle et al. (2009).

Model description. MAESTRA is a threedimensional process-based model that computes transpiration, photosynthesis, and absorbed radiation within individual tree crowns. Specific to this study, a modified version previously validated to estimate deciduous tree transpiration (Bauerle et al., 2002; Bowden and Bauerle, 
2008) and within-crown light interception (Bauerle et al., 2004) was used. Each genotype's leaf physiological and morphological difference was parameterized with clonal-specific parameters. During the scaling process, MAESTRA scaled up leaf-level biochemical and energy balance properties that were linked with stomatal gas regulation both spatially and temporally (Bowden and Bauerle, 2008). This characteristic was also used to scale up genotype-specific transpiration $(E)$ responses and to analyze the physiological and morphological regulation of $E$ among genotypes. A full description of the model is beyond the scope of this article; however, detailed descriptions and references to model components can be found in Emhart et al. (2007) and Reynolds et al. (2009).

Model validation tests. Predicting leaf to whole crown transpiration (Bauerle et al., 2002, 2009; Bowden and Bauerle, 2008), withincrown light interception (Bauerle et al., 2004), and whole-tree $\mathrm{CO}_{2}$ exchange (Reynolds et al., 2009) with MAESTRA has been previously demonstrated in red maple cultivars.

Separating the morphologic versus physiologic leaf and canopy transpiration factors. MAESTRA was used to scale up leaf transpiration to the whole crown of a simulated 20-m tall mature deciduous canopy. The canopy was vertically stratified into 10 equal layers (2-m depth per layer) and $g_{\mathrm{s}}$ was estimated according to the Leuning (1995) submodel. We evaluated the vertical effects of horizontal wind speed, air temperature, and $L_{\mathrm{w}}$ on canopy transpiration profiles when forced convection is present. We held genotype physiological and morphological parameters constant at the mean (Table 1) and varied $L_{\mathrm{w}}$. Simulations were conducted using the minimum and maximum $L_{\mathrm{w}} \mathrm{S}$ (SR: $3.98 \mathrm{~cm}$ versus $\mathrm{AB}: 10.18 \mathrm{~cm}$ ) at two different growth temperatures (20 versus $35{ }^{\circ} \mathrm{C}$ ) to assess within-species $L_{\mathrm{w}}$ effects on transpiration. In addition, genotype-specific transpiration response curves were created from polynomial regressions over a range of possible broadleaf plant $L_{\mathrm{w}} \mathrm{S}$ at genotype-specific physiology parameters reported in Table 1 .

\section{RESULTS}

Simulated effects of air temperature, wind speed, and leaf width within the canopy. At moderate to slow canopy surface wind velocity $\left(5 \mathrm{~m} \cdot \mathrm{s}^{-1}\right.$ or less), $L_{\mathrm{w}}$ has greater influences on transpiration under higher $\left(35^{\circ} \mathrm{C}\right.$ as opposed to $20{ }^{\circ} \mathrm{C}$ ) air temperature conditions; however, $L_{\mathrm{w}}$ effects on transpiration are diminished in the upper portions of the canopy as air temperature decreases (Fig. 1A). The same holds true at slower wind velocities $(0.2$ $\mathrm{m} \cdot \mathrm{s}^{-1}$ or less), except, at lower air temperatures leaves with a smaller $L_{\mathrm{w}}$ still transpire more at all canopy depths (Fig. 1). The difference between a $5 \mathrm{~m} \cdot \mathrm{s}^{-1}$ versus $0.2 \mathrm{~m} \cdot \mathrm{s}^{-1}$ wind velocity at the canopy surface can cause transpiration to increase by $\approx 0.75 \mathrm{mmol} \cdot \mathrm{m}^{-2} \cdot \mathrm{s}^{-1}$ (compare Figs. 1A and 1B). However, regardless of air temperature, $L_{\mathrm{w}}$ effects on transpiration are greater at lower wind speeds (compare Figs. 1A and 1B).

Table 1. Species mean ( $n=5 \pm$ SE of genotypes with genotypic range; each genotype value was derived from the mean of five replicate trees) parameter values used in MAESTRA.

\begin{tabular}{lcc}
\hline Parameter and units & Mean & Range \\
\hline$L_{\mathrm{t}}(\%)$ & $4.69 \pm 0.23$ & 1.21 \\
$L_{\mathrm{r}}(\%)$ & $8.97 \pm 0.25$ & 1.39 \\
$L_{\mathrm{w}}(\mathrm{cm})$ & $7.48 \pm 0.96$ & 6.2 \\
$W_{\mathrm{e}}($ dimensionless $)$ & $1.0 \pm 0.04$ & 0.2 \\
$\theta($ dimensionless & $0.908 \pm 0.01$ & 0.09 \\
$J_{\max }\left(\mu \mathrm{mol} \cdot \mathrm{m}^{-2} \cdot \mathrm{s}^{-1}\right)$ & $175.22 \pm 10.41$ & 64.73 \\
$E_{\mathrm{j}}\left(\mathrm{J} \cdot \mathrm{mol}^{-1}\right)$ & $52,080 \pm 802.69$ & 6200 \\
$\tau_{\mathrm{j}}\left(\mathrm{K}^{-1} \cdot \mathrm{mol}^{-1}\right)$ & $639 \pm 0.52$ & 3 \\
$\alpha\left(\mathrm{mol} \mathrm{e}^{-1} \mathrm{~mol}^{-1} \mathrm{PAR}_{\mathrm{a}}\right)$ & $0.2502 \pm 0.01$ & 0.0628 \\
$V_{\mathrm{cmax}}\left(\mu \mathrm{mol} \cdot \mathrm{m}^{-2} \cdot \mathrm{s}^{-1}\right)$ & $69.06 \pm 2.57$ & 15.76 \\
$E_{\mathrm{v}}\left(\mathrm{J} \cdot \mathrm{mol}^{-1}\right)$ & $52,040 \pm 1,832.29$ & 10,300 \\
$R_{\mathrm{d}}\left(\mu \mathrm{mol} \cdot \mathrm{m}^{-2} \cdot \mathrm{s}^{-1}\right)$ & $3.58 \pm 0.15$ & 0.94 \\
$\Gamma\left(\mu \mathrm{mol} \cdot \mathrm{m}^{-2} \cdot \mathrm{s}^{-1}\right)$ & $99.64 \pm 2.51$ & 15.18 \\
$g_{1}\left(\mathrm{~mol} \cdot \mathrm{m}^{-2} \cdot \mathrm{s}^{-1}\right)$ & $6.41 \pm 0.35$ & 1.96 \\
$g_{\mathrm{o}}\left(\mathrm{mol} \cdot \mathrm{m}^{-2} \cdot \mathrm{s}^{-1}\right)$ & $0.0426 \pm<0.00$ & 0.013 \\
\hline
\end{tabular}

Parameter abbreviations: $L_{\mathrm{t}}=$ leaf PAR transitivity; $L_{\mathrm{r}}=$ leaf PAR reflectance; $L_{\mathrm{w}}=$ leaf width; $W_{\mathrm{e}}=$ wind speed extinction coefficient; $\theta=$ convexity parameter of the light response; $J_{\max }=$ the maximum electron transport rate; $E_{\mathrm{j}}=$ activation energy temperature response of $J_{\max } ; \tau_{\mathrm{j}}=$ entropy term in temperature response of $J_{\max } ; \alpha=$ absorbed PAR $-\mathrm{PAR}_{\mathrm{a}}=$ quantum yield of electron transport; $V_{\text {cmax }}=$ the maximum rate of carboxylation; $E_{\mathrm{v}}=$ activation energy temperature response of $V_{\mathrm{cmax}} ; \Gamma=$ carbon dioxide compensation point; $R_{\mathrm{d}}=$ dark respiration; $g_{1}=$ genotype slope coefficient; $g_{\mathrm{o}}=$ minimum stomatal conductance.

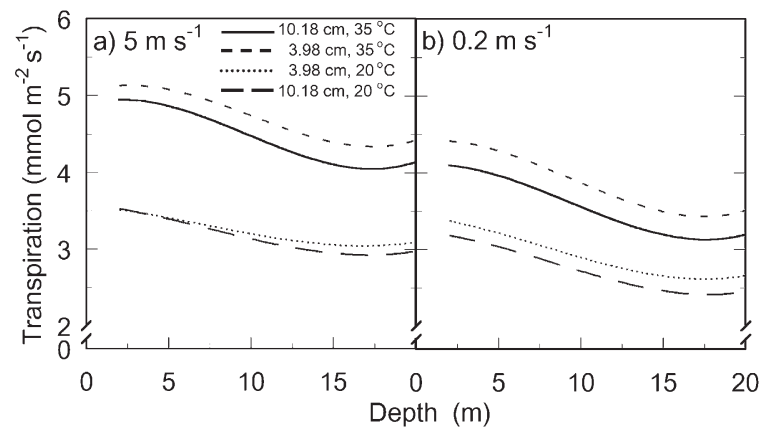

Fig. 1. Vertical depth from the canopy surface versus predicted transpiration profiles as a function of air temperature and leaf width $\left(L_{\mathrm{w}}\right)$ at two canopy surface wind speeds: (A) $5 \mathrm{~m} \cdot \mathrm{s}^{-1}$ and $(\mathbf{B}) 0.2 \mathrm{~m} \cdot \mathrm{s}^{-1}$. Transpiration is calculated for two different air temperatures and $L_{\mathrm{w}}$ where the solid line depicts a $10.18-\mathrm{cm} L_{\mathrm{w}}$ at $35^{\circ} \mathrm{C}$, the line with short dashes is $3.98 \mathrm{~cm} L_{\mathrm{w}}$ at $35^{\circ} \mathrm{C}$, the line with long dashes is $10.18 \mathrm{~cm} L_{\mathrm{w}}$ at $20^{\circ} \mathrm{C}$, and the dotted line is $3.98 \mathrm{~cm} L_{\mathrm{w}}$ at $20^{\circ} \mathrm{C}$. Simulations were conducted under constant conditions of relative humidity $=60 \%$ and photosynthetic photon flux $=1500 \mu \mathrm{mol} \cdot \mathrm{m}^{-2} \cdot \mathrm{s}^{-1}$ at a leaf area index $=1$.

Relationship among leaf width, leaf minus air temperature, horizontal wind speed, and transpiration. The model was used to assess the influence of horizontal wind speed on the distribution of transpiration along a vertical canopy depth profile at three different leaf area indexes (LAIs) and two different air temperatures using the narrowest and widest $L_{\mathrm{w}} \mathrm{s}$ among the five genotypes. The simulation showed the impact of changes in LAI and how the leaf-air temperature difference is lowered as wind speed increases (compare Figs. 2A-C and 2D-F). As a result of elevated temperature effects on VPD and wind speed effects on boundary layer conductance, transpiration increased with temperature and wind speed. Faster wind velocities also increased leaf heat dissipation rates. Hence, $L_{\mathrm{w}}$ effects on the leaf-air temperature difference were larger at lower wind speeds and elevated temperature (compare Figs. 2C and $2 \mathrm{~F}$ ). Clearly, these differences illustrate $L_{\mathrm{w}}$ and within-canopy depth effects on transpiration at contrasting air temperatures but identical physiological profiles (Fig. 2). The transpiration differences among changes in canopy position, LAI, and $L_{\mathrm{w}}$ manifest as $L_{\mathrm{w}}$ effects on leaf-air temperature differences and subsequent effects on long wave re-radiation as a function of leaf temperature, in which the divergent $L_{\mathrm{w}} \mathrm{s}$ in red maple caused $\approx 25 \%$ difference in transpiration at wind speeds of $\approx 5 \mathrm{~m} \cdot \mathrm{s}^{-1}$ and thus a more efficient heat transfer in the smaller leaf (compare Fig. 2 and Fig. $3)$. Figure 3 further illustrates that the leaf-air temperature difference and, hence, loss of long-wave radiation by the leaves is nonlinearly related to wind speed.

Effects of genotype morphology and physiology on the transpiration within a crown. The transpiration responses to changes in $L_{\mathrm{w}}$ were unique to each genotype across a range of simulated $L_{\mathrm{w}}$ sizes (Fig. 4). The genotype with the smallest $L_{\mathrm{w}}(\mathrm{SR})$ transpired more water than the genotype with the largest (AB) under identical environmental conditions (Fig. $4)$. Under inherent morphology and physiology conditions, SR was estimated to transpire 


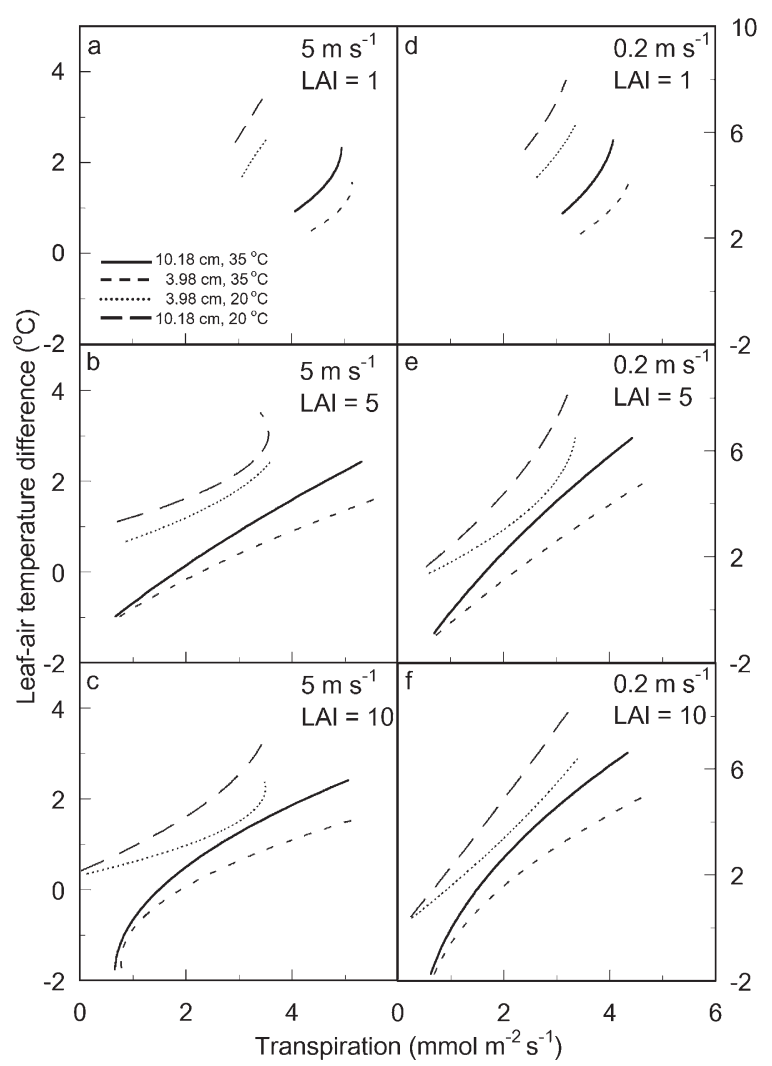

Fig. 2. Predicted transpiration crown profiles as a function of air temperature and leaf width $\left(L_{\mathrm{w}}\right)$ versus the predicted leaf temperature to measured air temperature difference at two different wind speeds and three canopy leaf area index (LAI) values. (A-C) Wind speed $=5 \mathrm{~m} \cdot \mathrm{s}^{-1}$ and (D-F) $0.2 \mathrm{~m} \cdot \mathrm{s}^{-1}$. (A, D) $\mathrm{LAI}=1,(\mathbf{B}, \mathbf{E})=5$, and $(\mathbf{C}, \mathbf{F})=10$ at constant environmental conditions (relative humidity $=60 \%$ and photosynthetic photon flux $\left.=1500 \mu \mathrm{mol} \cdot \mathrm{m}^{-2} \cdot \mathrm{s}^{-1}\right)$. Transpiration is calculated for two different temperatures and $L_{\mathrm{w}}$ where the solid line depicts a $10.18 \mathrm{~cm} L_{\mathrm{w}}$ at $35^{\circ} \mathrm{C}$, the line with short dashes is $3.98 \mathrm{~cm} L_{\mathrm{w}}$ at $35^{\circ} \mathrm{C}$, the line with long dashes is $10.18 \mathrm{~cm} L_{\mathrm{w}}$ at $20^{\circ} \mathrm{C}$, and the dotted line is $3.98 \mathrm{~cm}$ $L_{\mathrm{w}}$ at $20^{\circ} \mathrm{C}$. Please note differences in y-axis scale between $\mathbf{A}-\mathbf{C}$ versus D-F.

$\approx 2 \mathrm{mmol} \cdot \mathrm{m}^{-2} \cdot \mathrm{s}^{-1}$ more than $\mathrm{AB}$. However, when the SR $L_{\mathrm{w}}$ was increased to match that of $\mathrm{AB}$, the physiological variation between genotypes indicated that transpiration remains $\approx 1.5 \mathrm{mmol} \cdot \mathrm{m}^{-2} \cdot \mathrm{s}^{-1}$ greater in SR as compared with $\mathrm{AB}$ (Fig. 4). Although physiological factors appear to add to the greater transpiration in SR as compared with $\mathrm{AB}$ at equal $L_{\mathrm{w}}$, $L_{\mathrm{w}}$ differences alone cause an additional $25 \%$ increase/decrease in SR versus $\mathrm{AB}$ transpiration under moderate wind speed conditions $\left(\approx 5 \mathrm{~m} \cdot \mathrm{s}^{-1}\right)$. Alternatively, other genotypes converge to approximate equal transpiration rates when $L_{\mathrm{w}}$ is uniform (e.g., cv. AF and RS). Thus, the genotypes AB, RS, and OG illustrate the phenomenon termed equifinality (Franks et al., 1997) in that a similar simulation result can be achieved with different parameter combinations. Nonetheless, the simulation results illustrate that physiological parameters can counterbalance morphological and vice versa to yield similar transpiration estimates.

\section{DISCUSSION}

Our model results indicate that the aerodynamic and physiological controls on transpiration interact. Model simulations showed that variation in physiological attributes can counterbalance morphological transpiration controls (Fig. 4). Alternatively, morphology and physiology attributes can work in the same direction to elevate or depress transpiration (e.g., SR versus AB) because leaf morphology and physiology often vary together (Niinemets et al., 1998). Changes in both morphology and physiology may occur in plants where adaptations are required to deal with potential evapotranspiration in very different climates. Nevertheless, multiple factors appear to be involved in regulating transpiration.

Simulation estimates indicated that transpiration increased with decreasing $L_{\mathrm{w}}$ and vice versa; however, physiological factors can also add to the transpiration differences among genotypes (Fig. 4). Nonetheless, we found that the $L_{\mathrm{w}}$ effect on transpiration was important at both the crown and canopy scale and among genotypes. The genotype with the smallest $L_{\mathrm{w}}$ (SR) had the greatest rates of transpiration among all the genotypes and perhaps not consequently SR originated from the warmest climate. Moreover, when red maple genotypes were compared at their inherent physiology, the transpiration differences among genotypes still fell along a gradient in $L_{\mathrm{w}}$ (Fig. 4). Therefore, our results support the hypothesis that in a warmer climate, the red maple genotype with smaller leaves may have an advantage over larger-leaved genotypes resulting from an increased boundary layer con-

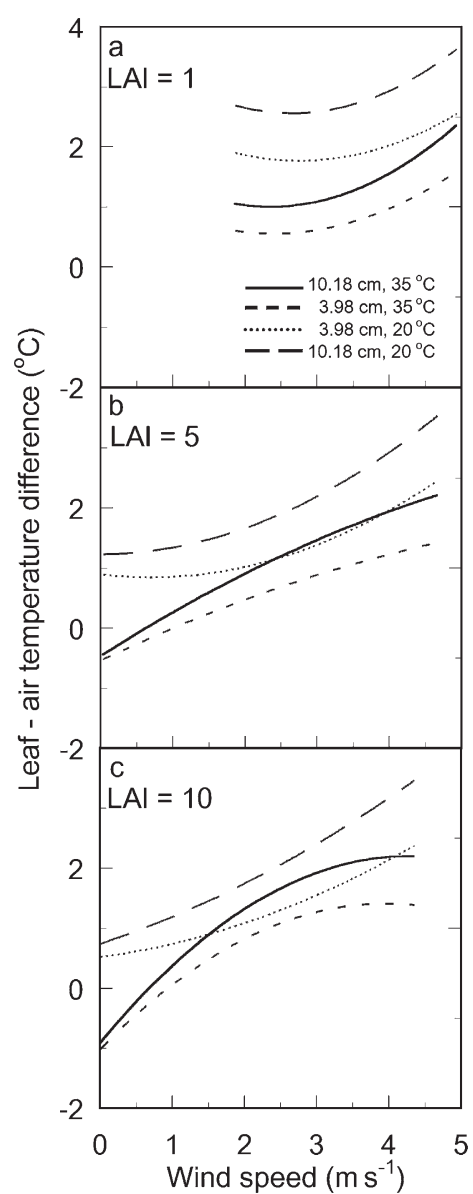

Fig. 3. Predicted leaf temperature to measured air temperature difference crown profiles as a function of wind speed, air temperature, and leaf width $\left(L_{\mathrm{w}}\right)$ at three different canopy leaf area index (LAI) values. (A) $\mathrm{LAI}=1,(\mathbf{B})=5$, and $(\mathbf{C})=10$ at constant environmental conditions (relative humidity $=60 \%$ and photosynthetic photon flux $=$ $\left.1500 \mu \mathrm{mol} \cdot \mathrm{m}^{-2} \cdot \mathrm{s}^{-1}\right)$. Leaf temperature to measured air temperature difference is calculated for two different air temperatures and $L_{\mathrm{w}}$ in which the solid line depicts a $10.18-\mathrm{cm} L_{\mathrm{w}}$ at $35^{\circ} \mathrm{C}$, the line with short dashes is $3.98 \mathrm{~cm} L_{\mathrm{w}}$ at $35^{\circ} \mathrm{C}$, the line with long dashes is $10.18 \mathrm{~cm} L_{\mathrm{w}}$ at $20^{\circ} \mathrm{C}$, and the dotted line is $3.98 \mathrm{~cm} L_{\mathrm{w}}$ at $20^{\circ} \mathrm{C}$.

ductance and the ability to prevent leaf temperature from rising well above ambient in non-limiting soil moisture conditions (Royer et al., 2008). This $L_{\mathrm{w}}$ attribute would seem highly adaptive for a tree with a canopy more exposed to solar radiation, like in home landscapes or intensive production horticulture sites. Additionally, smaller leaves could be viewed as an easily identifiable trait when breeding for improved productivity in agricultural crops for a future warmer world.

Microclimate influences leaf size through a variety of environmental cues at multiple scales (Granier and Tardieu, 2009). At the leaf scale, cell number or size can change in response to environmental conditions, whereas at the whole-plant level, leaf size is more likely to change than leaf number (e.g., Aguirrezabal et al., 2006; Hovenden and Vander Schoor, 2004; Karamanos et al., 1982; Oleksyn et al., 1998). Relative to our findings at the canopy 


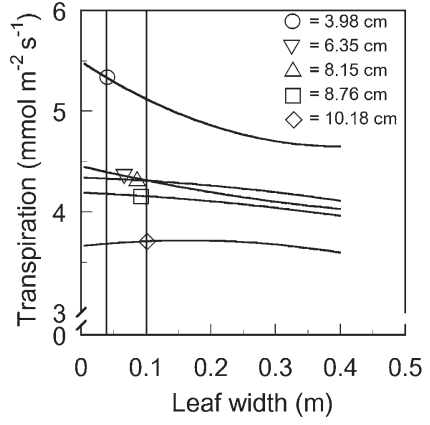

Fig. 4. Predicted leaf-level transpiration response for five genotypes to variations in leaf width $\left(L_{\mathrm{w}}\right)$. Results were generated using individual genotype-specific physiology parameters at constant environmental conditions (air temperature $=$ $25^{\circ} \mathrm{C}$, relative humidity $=60 \%$, photosynthetic photon flux $=1500 \mu \mathrm{mol} \cdot \mathrm{m}^{-2} \cdot \mathrm{s}^{-1}$, and wind speed $\left.=5 \mathrm{~m} \cdot \mathrm{s}^{-1}\right)$. Symbol locations depict the genotype transpiration at inherent $L_{\mathrm{w}}$ (reported in legend) and physiology. The non-linear lines that intersect each symbol illustrate the predicted genotype transpiration response to alterations in $L_{\mathrm{w}}$ Vertical bars bracket the range of $L_{\mathrm{w}}$ observed across the genotypes in this study. Red maple genotype symbols are as follows: 'Summer Red' $(\bigcirc)$, 'Autumn Flame' $(\nabla)$, 'Red Sunset' $(\triangle)$, 'October Glory' $(\square)$, and 'Autumn Blaze' $(\diamond)$.

scale, the lower the LAI and slower the wind speed, the greater the $L_{\mathrm{w}}$ impact on transpiration. Thus, changes to leaf size can mediate transpiration in response to environmental stimuli (e.g., Gates, 1968). In addition, changes in $L_{\mathrm{w}}$ can have a dramatic impact on both transpiration (assuming no changes in $g_{\mathrm{s}}$ ) and leaf-air temperature differences. Our findings suggest that on exposed warm sites, $L_{\mathrm{w}}$ will have a substantial effect on transpiration to the extent that it may provide a means to prevent the leaf temperature from rising to a harmful level. Hence, changes in $L_{\mathrm{w}}$ can play a substantial part in modulating leaf temperature and transpiration.

\section{CONCLUSIONS}

Increases in temperature resulting from climate change will impact plant transpiration and water use. Selection of trees with smaller leaves will be a better fit for hotter climates. Smaller leaves have a higher boundary layer conductance that increases the rate of water vapor and heat transport, appreciably influencing leaf temperature in favor of a smaller leaf in warmer climates.

\section{Literature Cited}

Aguirrezabal, L., S. Bouchier-Combaud, A Radziejwoski, M. Dauzat, S.J. Cookson, and C. Granier. 2006. Plasticity to soil water deficit in arabidopsis thaliana: Dissection of leaf development into underlying growth dynamic and cellular variables reveals invisible phenotypes. Plant Cell Environ. 29:2216-2227.

Bauerle, W.L., J.D. Bowden, M.F. McLeod, and J.E. Toler. 2004. Modeling intra-crown and intra-canopy interactions in red maple: Assessment of light transfer on carbon dioxide and water vapor exchange. Tree Physiol. 24:589597.

Bauerle, W.L., J.D. Bowden, and G.G. Wang. 2007. The influence of temperature on withincanopy acclimation and variation in leaf photosynthesis and respiration: Spatial acclimation to microclimate gradients among thermally divergent Acer rubrum L. genotypes. J. Exp. Bot. 58:3285-3298

Bauerle, W.L., J.D. Bowden, G.G. Wang, and M.A. Shahba. 2009. Exploring the importance of within-canopy spatial temperature variation on transpiration predictions. J. Exp. Bot. 60 3665-3676.

Bauerle, W.L., J.B. Dudley, and L.W. Grimes 2003. Genotypic variation in photosynthesis, water use, and light absorption among red and Freeman cultivars in response to drought stress. J. Amer. Soc. Hort. Sci. 128:337-342.

Bauerle, W.L., C.J. Post, M.F. McLeod, J.B Dudley, and J.E. Toler. 2002. Measurement and modeling of the transpiration of a temperate red maple container nursery. Agr. Forest Meteorol. 114:45-57.

Bowden, J.D. and W.L. Bauerle. 2008. Measuring and modeling the variation in species specific transpiration in temperate deciduous hardwoods. Tree Physiol. 28:1675-1683.

Bunce, J.A. 1985. Effect of boundary layer conductance on the response of stomata to humidity. Plant Cell Environ. 8:55-57.

Emhart, V.I., T.A. Martin, T.L. White, and D.A. Huber. 2007. Clonal variation in crown structure, absorbed photosynthetically active radiation and growth of loblolly pine and slash pine. Tree Physiol. 27:421-430.

Franks, S.W., K.J. Beven, P.F. Quinn, and I.R. Wright. 1997. On the sensitivity of soil-vegetation-atmosphere transfer (SVAT) schemes: Equifinality and the problem of robust calibration. Agr. Forest Meteorol. 86:63-75.

Gates, D.M. 1968. Transpiration and leaf temperature. Annu. Rev. Plant Physiol. 19:211-238.

Granier, C. and F. Tardieu 2009. Multi-scale phenotyping of leaf expansion in response to environmental changes: the whole is more than the sum of parts. Plant Cell Environ. 32:1175-1184.

Hinckley, T.M., J.R. Brooks, J. Čermák, R. Ceulemans, J. Kučera, F.C. Meinzer, and D.A. Roberts. 1994. Water flux in a hybrid poplar stand. Tree Physiol. 14:1005-1018.
Hovenden, M.J. and J.K. Vander Schoor. 2004. Nature vs nurture in the leaf morphology of Southern beech, Nothofagus cunninghamii (Nothofagaceae). New Phytol. 161:585-594.

Jarvis, P.G. and K.G. McNaughton. 1986. Stomatal control of transpiration: Scaling up from leaf to region. Adv. Ecol. Res 15:1-49.

Karamanos, A.J., J. Elston, and R.M. Wadsworth 1982. Water stress and leaf growth of field beans (Vicia faba L.) in the field: Water potentials and laminar expansion. Ann. Bot. (Lond.) 49:815-826.

Katul, G.G., S. Palmroth, and R. Oren. 2009. Leaf stomatal responses to vapour pressure deficit under current and $\mathrm{CO}_{2}$-enriched atmosphere explained by the economics of gas exchange. Plant Cell Environ. 32:968-979.

Leuning, R. 1995. A critical appraisal of a combined stomatal photosynthesis model for $\mathrm{C}_{3}$ plants. Plant Cell Environ. 18:339-355.

Meinzer, F.C., G. Goldstein, P. Jackson, N.M Holbrook, M.V. Gutierrez, and J. Cavelier. 1995. Environmental and physiological regulation of transpiration in tropical forest gap species: The influence of boundary layer and hydraulic properties. Oecologia 101:514-522.

Monteith, J.L. 1989. Reflection and review. Philos. Trans. R. Soc. Lond. B Biol. Sci. 324:433-436.

Monteith, J.L. and M.H. Unsworth. 2008. Principles of environmental physics. 3rd Ed. Academic Press, Burlington, MA.

Niinemets, Ü., O. Kull, and J.D. Tenhunen. 1998. An analysis of light effects on foliar morphology, physiology, and light interception in temperate deciduous woody species of contrasting shade tolerance. Tree Physiol. 18:681696.

Oleksyn, J., J. Modrzynski, M.G. Tjoelker, R. Zytkowiak, P.B. Reich, and P. Karolewski. 1998. Growth and physiology of Picea abies populations from elevational transects: Common garden evidence for altitudinal ecotypes and cold adaptation. Funct. Ecol. 12:573-590.

Raschke, K. 1956. Über die physikalischen Beziehungen zwischen Wärmeübergangszahl, Strahlungsaustausch, Temperatur und Transpiration eines Blattes. Planta 48:200-238.

Reynolds, R.F., W.L. Bauerle, and Y. Wang. 2009 Simulating carbon dioxide exchange rates of deciduous tree species: Evidence for a general pattern in biochemical changes and water stress response. Ann. Bot. (Lond.) 104:775-784.

Royer, D.L., J.C. McElwain, J.M. Adams, and P. Wilf. 2008. Sensitivity of leaf size and shape to climate within Acer rubrum and Quercuskelloggii. New Phytol. 179:808-817.

Schuepp, P.H. 1993. Leaf boundary layers. New Phytol. 125:477-507.

Schlichting, H. and K. Gersten. 2004. BoundaryLayer theory. 8th Ed. Springer, Berlin.

Wang, Y.P. and P.G. Jarvis. 1990. Description and validation of an array model-MAESTRO. Agr. Forest Meteorol. 51:257-280. 